ORIGINAL ARTICLE

\title{
Comparison of injury case fatality rates in the United States and New Zealand
}

\author{
R Spicer, T Miller, J Langley, S Stephenson
}

Injury Prevention 2005;11:71-76. doi: 10.1136/ip.2004.005579

See end of article for authors' affiliations .....................

Correspondence to: Dr R Spicer, 11710 Beltsville Drive, Suite 300, Beltsville, MD 20705, USA; spicer@pire.org

\begin{abstract}
Objective: To compare injury case fatality rates in the United States (US) with New Zealand (NZ) to guide future information collection, research, and evaluation.

Design: Using NZ (1992-96) and US (1996-98) mortality censuses, NZ national 1992-96 hospital discharge censuses, and US 1996-98 National Hospital Discharge Survey data, the authors compared case fatality rates by mechanism and intent of injury and age group. The analysis was restricted to severe injuries (AIS $\geqslant 3$ ).

Subjects: NZ (1992-96) and US (1996-98) populations.

Main outcome measures: Ratio of case fatality rates in NZ versus the US (RCFR(NZ:US)).

Results: Overall, among cases meeting the study criteria, unintentional injuries were 1.57 times more likely fatal in NZ and intentional assault injuries were 1.14 times more likely to be fatal in the US. Firearms were involved in $50 \%$ of US assaults versus $8 \%$ of NZ assaults. By mechanism, cutting/piercing injuries were 1.86 , firearm injuries were 1.41, and motor vehicle injuries were 1.44 times more to be likely fatal in NZ. Natural/environmental injuries $\left(R C F R_{N Z: U S}=0.57\right)$, unintentional poisonings $\left(R C F R_{N Z: U S}=0.26\right)$, and unintentional suffocations (RCFR NZ:US $=0.67$ ) were significantly more likely to be fatal in the US.

Conclusions: Possible reasons for the observed results include: differences in geography and proportion of population in rural areas, trauma system differences, road design and vehicle types, seat belt use, larger role of firearms in US assaults, coding practices, policies, and environmental factors. Disparities evoke hypotheses to test in future research that will guide priority setting and intervention.
\end{abstract}

njury is a leading cause of death and hospitalization worldwide. International comparisons provide clues to political, social, economic, cultural, and other country specific factors in injury control. In contrast to comparative studies of mortality rates, which provide information for primary prevention, comparisons of case fatality rates provide clues to factors that influence the survival of the injury, including severity and secondary prevention. This study compares injury case fatality rates (CFRs) in the United States (US) with New Zealand (NZ).

\section{METHODS}

New Zealand cases were based on national 1992-96 hospital discharge and mortality censuses. US fatal cases came from the 1996 through 1998 vital statistics mortality censuses (accessed via WISQARS ${ }^{1}$ ) and hospitalized cases were based on National Hospital Discharge Survey (NHDS) data, a nationally representative sample of hospital discharges in the US. These years of NHDS data were used because they overlap with the NZ data and were the first years that NHDS included substantial injury cases that were coded by external cause (E coded). In both NZ and the US we assume the mortality data capture all deaths.

A non-fatal hospitalized injury case was defined as having a principal diagnosis between 800 and 995 among the International Classification of Diseases, Ninth Revision (ICD-9) nature of disease diagnoses ${ }^{2}$ and not discharged dead. Deaths were identified when the principal cause of death was recorded as an ICD-9 E code. For each data set, mechanism of injury was deduced from the first or only E code assigned to each case.

Only $63 \%$ of NHDS cases were E coded. We statistically modeled injury intent and cause on the remaining cases. We inferred cause probability distributions by age group, sex, and principal diagnosis for missing causes based on the E coded cases. The more diagnosis fields filled, the less likely the case was E coded. We therefore modeled injury intent and cause in three groups: those with 1 or 2 diagnoses, those with 3 through 5 diagnoses, and those with 6 or 7 diagnoses. Where 6 or all 7 fields were used, an E code was rarely included. For these cases we inferred causation probabilities by age group, sex, and diagnosis using data for E coded cases with at least six diagnoses in 1993-95 state hospital discharge censuses that we pooled from California, Maryland, Missouri, New York, and Vermont. In the pooled file, $96 \%$ of injury cases were E coded. ${ }^{3}$

Case fatality rate (CFR) was defined as the percentage of injuries that are fatal and based on the formula

$\mathrm{CFR}=$ (number of fatal injuries) $/$ (number of fatal injuries + number of hospitalized injuries meeting the study criteria).

Country CFRs were compared using the CFR ratio in NZ versus the US (RCFR $(\mathrm{NZ:US)})$.

Selection bias was possible if admission procedures differed between the two countries. To minimize this bias, we selected severe cases with a maximum abbreviated injury severity (AIS) of 3 or greater. AIS measures threat to life and has been extensively evaluated. ${ }^{4}$ We assumed that virtually all injuries with maximum AIS 3 or greater are hospitalized, based on findings that $82 \%$ of all AIS 3-5 injuries seen in emergency departments in South Carolina, New Hampshire,

Abbreviations: AIS, Abbreviated Injury Severity; CFR, case fatality rate; E, external cause; FARS, Fatality Analysis Reporting System; HCUP, Healthcare Cost and Utilization Project; ICD-9, International Classification of Diseases, Ninth Revision; NHDS, National Hospital Discharge Survey; RCFR(NZ:US), ratio of case fatality rates, New Zealand divided by the United States. 
Table 1 Case fatality rates in New Zealand (1992-96) and the United States (1996-98) and ratios of case fatality rates (RCFRs) in NZ $v$ the US, by selected mechanisms and intent of injury (see table 3 for RCFR confidence intervals)

\begin{tabular}{|c|c|c|c|c|c|c|c|c|c|}
\hline \multirow[b]{2}{*}{ Mechanism } & \multicolumn{4}{|c|}{ New Zealand } & \multicolumn{4}{|c|}{ United States } & \multirow[b]{2}{*}{$\begin{array}{l}\text { Ratio of } \\
\text { CFR } \\
\text { NZ:US }\end{array}$} \\
\hline & Fatal & $\begin{array}{l}\text { Hospital } \\
\text { (non- } \\
\text { fatal) }\end{array}$ & Total & CFR & Fatal & $\begin{array}{l}\text { Hospital } \\
\text { (non- } \\
\text { fatal)† }\end{array}$ & Total & CFR & \\
\hline Cut/pierce & 156 & 255 & 411 & $38 \%$ & 8718 & 34095 & 42813 & $20 \%$ & $1.86^{*}$ \\
\hline Unintentional & 19 & 79 & 98 & $19 \%$ & 332 & 6766 & 7098 & $5 \%$ & $4.15^{*}$ \\
\hline Intentional assault & 97 & 144 & 24 & $40 \%$ & 6952 & 25897 & 32849 & $21 \%$ & $1.90^{*}$ \\
\hline Intentional self-harm & 38 & 31 & 69 & $55 \%$ & 1410 & 1136 & 2546 & $55 \%$ & 0.99 \\
\hline Fall & 1140 & 17327 & 18467 & $6 \%$ & 37894 & 1213116 & 1251010 & $3 \%$ & $2.04^{*}$ \\
\hline Unintentional & 1060 & 17310 & 18370 & $6 \%$ & 35745 & 1211967 & 1247712 & $3 \%$ & $2.01^{*}$ \\
\hline Intentional self-harm & 72 & 13 & 85 & $85 \%$ & 1866 & 138 & 2004 & $93 \%$ & 0.91 \\
\hline Fire/Burn & 205 & 232 & 437 & $47 \%$ & 12249 & 15807 & 28056 & $44 \%$ & 1.07 \\
\hline Fire & 190 & 72 & 262 & $73 \%$ & 11890 & 8617 & 20507 & $58 \%$ & $1.25^{*}$ \\
\hline Scald & 15 & 160 & 175 & $9 \%$ & 359 & 7190 & 7549 & $5 \%$ & $1.80^{*}$ \\
\hline Firearm & 452 & 36 & 488 & $93 \%$ & 97184 & 50292 & 147476 & $66 \%$ & $1.41^{*}$ \\
\hline Unintentional & 27 & 15 & 42 & $64 \%$ & 2981 & 9678 & 12659 & $24 \%$ & $2.73^{*}$ \\
\hline Intentional assault & 55 & 7 & 62 & $89 \%$ & 39087 & 29837 & 68924 & $57 \%$ & $1.56^{*}$ \\
\hline Intentional self-harm & 346 & 10 & 356 & $97 \%$ & 53156 & 6396 & 59552 & $89 \%$ & $1.09^{*}$ \\
\hline Machinery & 89 & 378 & 467 & $19 \%$ & 2999 & 11701 & 14700 & $20 \%$ & 0.93 \\
\hline Motor vehicle traffic & 2965 & 4448 & 7413 & $40 \%$ & 127430 & 332656 & 460086 & $28 \%$ & $1.44^{*}$ \\
\hline Motorcyclist & 371 & 914 & 1285 & $29 \%$ & 6561 & 23310 & 29871 & $22 \%$ & $1.31^{*}$ \\
\hline Occupant & 2134 & 2608 & 4742 & $45 \%$ & 100218 & 233663 & 333881 & $30 \%$ & $1.50^{*}$ \\
\hline Pedal cyclist & 80 & 164 & 244 & $33 \%$ & 2340 & 7770 & 10110 & $23 \%$ & 1.42 \\
\hline Pedestrian & 350 & 570 & 920 & $38 \%$ & 16526 & 41722 & 58248 & $28 \%$ & $1.34^{*}$ \\
\hline Natural/environmental & 56 & 165 & 221 & $25 \%$ & 4436 & 5617 & 10053 & $44 \%$ & $0.57^{*}$ \\
\hline Pedal cyclist, non-MV & 14 & 362 & 376 & $4 \%$ & 397 & 21726 & 22123 & $2 \%$ & $2.07^{*}$ \\
\hline Pedestrian, non-MV & 64 & 95 & 159 & $40 \%$ & 2761 & 5700 & 8461 & $33 \%$ & 1.23 \\
\hline Struck by/against & 177 & 1085 & 1262 & $14 \%$ & 4091 & 77432 & 81523 & $5 \%$ & $2.79^{*}$ \\
\hline Unintentional & 105 & 716 & 821 & $13 \%$ & 2936 & 42368 & 45304 & $6 \%$ & $1.97^{*}$ \\
\hline Intentional assault & 71 & 355 & 437 & $16 \%$ & 1127 & 35023 & 36150 & $3 \%$ & $5.21^{*}$ \\
\hline Transport, other & 195 & 909 & 1104 & $18 \%$ & 5875 & 48995 & 54870 & $11 \%$ & $1.65^{\star}$ \\
\hline $\begin{array}{l}\text { All the above mechanisms } \\
\text { combined } \neq\end{array}$ & 5513 & 25292 & 30805 & $18 \%$ & 304034 & 1817137 & 2121171 & $14 \%$ & $1.25^{\star}$ \\
\hline Unintentional & 4758 & 24702 & 29460 & $16 \%$ & 196271 & 1711757 & 1908028 & $10 \%$ & $1.57^{*}$ \\
\hline Intentional assault & 227 & 521 & 748 & $30 \%$ & 47870 & 91169 & 139039 & $34 \%$ & $0.88^{*}$ \\
\hline Intentional self-harm & 491 & 59 & 550 & $89 \%$ & 57332 & 8554 & 65886 & $87 \%$ & 1.03 \\
\hline \multicolumn{10}{|c|}{$\begin{array}{l}\text { †With maximum Abbreviated Injury Scale score greater than or equal to } 3 \text {. } \\
\text { tExcludes poisoning, drowning, suffocation, adverse events, other specified and classifiable, other specified and } \\
\text { not elsewhere classifiable, overexertion, and unspecified. } \\
\text { * } \mathrm{p} \leqslant 0.05 \text {. } \\
\text { Non-MV, non-motor vehicle related. }\end{array}$} \\
\hline
\end{tabular}

Maryland, and Nebraska during 1997-98 were hospitalized (an analysis conducted for this article).

For consistency, AIS was mapped onto both countries' hospital discharge data using the software program ICDMAP90.5 CFRs were then compared by mechanism of injury according to the primary $\mathrm{E}$ code and an internationally recommended E code framework. ${ }^{6}$ The analysis separated injury mechanisms into two categories. The first category restricted the analysis to cases with AIS scores greater than or equal to 3 for causes where ICDMAP-90 was able to translate the primary diagnosis into an AIS score in at least $50 \%$ of cases (cut/pierce, fall, fire/burn, firearm, machinery, motor vehicle, natural/environmental, overexertion, struck by/ against, and non-motor vehicle related pedestrian, bicycle, and other transport injuries). Diagnoses codes that can be translated into AIS by ICDMAP-90 include 800-904, 910-929, 940-957, and 959. The nature of injury codes most commonly associated with drowning/submersion (994), poisoning (960 through 989), and suffocation (933-934) are not translated into AIS by ICDMAP-90. We separately analyzed these causes and included all hospitalizations in the denominator, regardless of AIS. In separating these groups we assumed that cause groups are associated with certain diagnosis codes. Although not always a valid assumption, the NHDS data show that over $96 \%$ of cases with nature of injury codes excluded from the ICDMAP-90 program were poisonings, drownings, or suffocations, or were in the categories excluded from this study (unspecified, other specified, or adverse events).

Road user type was unknown in $22 \%$ of motor vehicle related deaths in the vital statistics data. Therefore, road user type was based on Fatality Analysis Reporting System (FARS) 1996-98 data for 126085 cases. FARS is a census of fatal traffic crashes in the US.

Although the NZ hospital discharge and mortality data and the US mortality data are all-case census data and not subject to sampling variability, they might be affected by random variation. Therefore we indicated in the tables when the number of cases was small (fewer than 50 overall), meaning caution should be taken when interpreting the results.

Ninety five percent confidence intervals of the CFR estimates and the associated RCFRs (NZ:US) $_{\text {were computed. }}$ In non-E coded cases the NHDS weights were split in order to represent the probabilities that the case represented various $\mathrm{E}$ codes. Although we could have used statistical software such as SUDAAN to compute standard errors, the split weight cases with inferred E codes would mislead the software, yielding erroneous standard errors. Therefore, standard errors were computed based on the weighted NHDS estimates and the published parameters (computed with SUDAAN). ${ }^{7}$ We strongly believe that this method provided the most appropriate standard errors.

Because imputing missing E codes in NHDS introduced an unknown level of inaccuracy, sensitivity analysis tested if the 
RCFRs $_{\text {(NZ:US) }}$ were consistent with RCFRs (NZ:US) $_{\text {computed }}$ using two alternate US data sources. One set of US CFRs were computed by applying the cause and intent distribution of injury cases in the 2000 Healthcare Cost and Utilization Project (HCUP) Nationwide Inpatient Sample database to the NHDS 1996-98 injury estimates. HCUP is a US population based sample of hospital care data. The 2000 data cover more states and are much more fully $\mathrm{E}$ coded than data from earlier years. Of the estimated 502505 injury related records in the 2000 HCUP file, $83 \%$ are E coded. A second set of CFRs were computed from pooled censuses of all hospital discharges and deaths in all 20 states where 1997 E coded hospital discharge and multiple cause of death data were easily obtainable (Arizona, California, Florida, Maine, Maryland, Massachusetts, Michigan, Nebraska, New Hampshire, New Jersey, New York, Pennsylvania, Rhode Island, South Carolina, Utah, Vermont, Virginia, Washington, Wisconsin, and Washington DC). Of the more than one million injury related records in this data file, $88 \%$ are E coded.

\section{RESULTS}

In NZ, from 1992 through 1996, 8832 people were fatally injured (0.48 per 1000 population per year), and 26719 severe non-fatal injuries (AIS 3 and greater) resulted in hospitalization (1.4 per 1000 population per year). From 1996 though 1998 in the US, 147126 people were fatally injured (0.19 per 1000 population per year) and an estimated 693005 severe non-fatal injuries were hospitalized (0.87 per 1000 population per year). Excluding the mechanisms of injury with less than $50 \%$ of primary diagnoses translatable to AIS, 5513 of 25292 injuries were fatal in NZ (18\%) versus 304034 of 2121171 injuries in the US (14\%) $\left(\mathrm{RCFR}_{(\mathrm{NZ}: \mathrm{US})}=1.25\right.$; 95\% CI 1.22 to 1.28) (table 1). Larger differences were observed when cases were examined by mechanism and injury intent (table 1). Notably, unintentional injuries were 1.57 times more likely fatal in NZ (95\% CI 1.53 to 1.61 ) and intentional assault injuries were 1.14 times more likely fatal in the US $\left(\right.$ RCFR $_{\text {(NZ:US) }}=0.88 ; 95 \%$ CI 0.81 to 0.95$)$. RCFRs $_{\text {(NZ:US) }}$ by age were similar in the two countries. $\mathrm{RCFR}_{\text {(NZ:US) }}$ was highest among injuries to those 65 years and older (table available upon request).

Cutting/piercing injuries were 1.86 (95\% CI 1.56 to 2.17 ) times more likely to be fatal in NZ compared with the US. In the US a greater proportion of cutting/piercing injuries were attributed to assault $(77 \% v 59 \%)$. RCFR $($ NZ:Us) was particularly high among unintentional cutting/piercing injuries $\left(\operatorname{RCFR}_{(\mathrm{NZ}: \mathrm{US})}=4.15 ; 95 \%\right.$ CI 2.32 to 5.97$)$.
Firearm injuries were 1.41 times (95\% CI 1.32 to 1.49 ) more likely fatal in NZ compared with the US. Nearly threequarters (73\%) resulted from self-harm in NZ compared with $40 \%$ in the US. Stratifying by intent showed that RCFR (NZ:US) was highest for unintentional firearm injuries $\left(\operatorname{RCFR}_{(\mathrm{NZ}: \mathrm{US})}=2.73 ; 95 \% \mathrm{CI} 1.92\right.$ to 3.54$)$.

Motor vehicle related injuries were 1.44 (95\% CI 1.38 to 1.51) times more likely to be fatal in NZ compared with the US. RCFRs (NZ:US) were similar across road user types.

Fire/flame and scalding by hot substance injuries were slightly more likely fatal in the US. CFRs for machinery related and non-motor vehicle related pedestrian injuries were not significantly different between the two countries and NZ case counts were small.

The analysis of drowning/submersions, poisonings, and suffocations included all hospitalizations, regardless of maximum AIS. CFRs by cause were similar (table 2). However, significant differences were found when cause was stratified by intent. Unintentional poisonings were over three times more likely to be fatal in the US $\left(\mathrm{RCFR}_{\text {(NZ:US) }}=0.26,95 \%\right.$ CI 0.25 to 0.28$)$, while self-inflicted poisonings were nearly twice as likely to be fatal in NZ $\left(\mathrm{RCFR}_{\text {(NZ:US) }}=1.89 ; 95 \%\right.$ CI 1.77 to 2.01$)$. Although, overall, CFRs for suffocations were similar, unintentional suffocations were 1.5 times more likely to be fatal in the US $\left(\right.$ RCFR $_{\text {(NZ:Us) }}=0.67,95 \%$ CI 0.57 to 0.77$)$.

Table 3 summarizes the sensitivity analysis of RCFR (NZ:Us) estimates computed from two alternate US hospital discharge data sources. Of the alternate $\mathrm{RCFR}_{(\mathrm{NZ}: \mathrm{US})}$ estimates, most fall within the $95 \%$ confidence limits from the NHDS analysis. Those that do not are often quite close to these limits. In 71 of 72 cases the alternate ratios are consistent with the NHDS findings about whether the US or NZ has a significantly higher CFR. Overall, the sensitivity analysis increases our confidence that the differences observed are real and not artifacts of our E code inference.

\section{DISCUSSION}

Both countries have similar overall mortality rates (7.54 per $1000 \mathrm{NZ}$ population and 8.34 per 1000 US population) which are low relative to the rest of the world. ${ }^{8}$ However, rates of fatal and severe non-fatal injury were substantially lower in the US. Injury CFRs in NZ and the US differ depending on cause of injury. We present possible explanations in order to generate research questions and identify data needs and directions for future evaluation and research.

The size and geography of the countries are strikingly different. In 1996 the NZ population was around 3.7 million versus approximately 265 million in the US. The US is a large

Table 2 Case fatality rates in New Zealand (1992-96) and the United States (1996) and ratios of case fatality rates in NZ $v$ the US, for drowning/submersions, poisonings, and suffocations

\begin{tabular}{|c|c|c|c|c|c|c|c|c|c|}
\hline \multirow[b]{2}{*}{ Mechanism } & \multicolumn{4}{|c|}{ New Zealand } & \multicolumn{4}{|c|}{ United States } & \multirow[b]{2}{*}{$\begin{array}{l}\text { Ratio of } \\
\text { CFR NZ:US }\end{array}$} \\
\hline & Fatal & $\begin{array}{l}\text { Hospital } \\
\text { (non-fatal)* }\end{array}$ & Total & CFR & Fatal & $\begin{array}{l}\text { Hospital } \\
\text { (non- } \\
\text { fatal)* }\end{array}$ & Total & CFR & \\
\hline Drowning/submersion & 550 & 562 & 1112 & $49 \%$ & 14451 & 13376 & 27827 & $52 \%$ & 0.95 \\
\hline Unintentional & 472 & 551 & 1023 & $46 \%$ & 12416 & 13273 & 25689 & $48 \%$ & 0.95 \\
\hline Poisoning & 1177 & 16420 & 17597 & $7 \%$ & 52769 & 714201 & 766970 & $7 \%$ & 0.97 \\
\hline Unintentional & 107 & 4710 & 4817 & $2 \%$ & 30474 & 332486 & 362960 & $8 \%$ & $0.26 \dagger$ \\
\hline Intentional self-harm & 1002 & 11108 & 12110 & $8 \%$ & 15280 & 334196 & 349476 & $4 \%$ & $1.89+$ \\
\hline Undetermined & 59 & 580 & 639 & $9 \%$ & 6792 & 47086 & 53878 & $13 \%$ & $0.73+$ \\
\hline Suffocation & 1137 & 903 & 2040 & $56 \%$ & 32243 & 38143 & 70386 & $46 \%$ & $1.22 \dagger$ \\
\hline Unintentional & 177 & 751 & 928 & $19 \%$ & 13325 & 33410 & 46735 & $29 \%$ & $0.67 \dagger$ \\
\hline Intentional self-harm & 930 & 121 & 1051 & $88 \%$ & 16469 & 4141 & 20610 & $80 \%$ & 1.11 \\
\hline
\end{tabular}


Table $395 \%$ confidence intervals for the relative case fatality rates (NZ:US) and relative rate estimates from alternate US hospital data

\begin{tabular}{|c|c|c|c|c|c|}
\hline \multirow[b]{2}{*}{ Mechanism } & \multicolumn{3}{|c|}{ Primary analysisł } & \multirow{2}{*}{$\begin{array}{l}\text { RCFR }_{(\mathrm{NZ}: \text { US) }} \text { based on } \\
\text { HCUP distribution } \S\end{array}$} & \multirow{2}{*}{$\begin{array}{l}\text { RCFR }_{\text {(NZ:US) }} \text { based on } \\
20 \text { state HDD }\end{array}$} \\
\hline & $\mathrm{RCFR}_{\text {(NZ:US) }}$ & $95 \% \mathrm{C}$ & & & \\
\hline Cut/pierce ${ }^{*}$ & 1.86 & 1.56 & 2.17 & 1.57 & 1.56 \\
\hline Unintentional & 4.15 & 2.32 & 5.97 & 2.82 & 1.91 \\
\hline Intentional assault & 1.90 & 1.55 & 2.26 & 1.60 & 1.75 \\
\hline Intentional self-harm & 0.99 & 0.49 & 1.49 & 1.33 & 1.05 \\
\hline Fall* & 2.04 & 1.97 & 2.11 & 2.13 & 1.41 \\
\hline Unintentional & 2.01 & 1.95 & 2.08 & 2.11 & 1.40 \\
\hline Fire/burn* & 1.07 & 0.89 & 1.26 & 0.78 & 0.95 \\
\hline Fire & 1.25 & 1.04 & 1.47 & 0.97 & 1.13 \\
\hline Scald & 1.80 & 1.03 & 2.57 & 1.05 & 1.07 \\
\hline Firearm* & 1.41 & 1.32 & 1.49 & 1.38 & 1.39 \\
\hline Unintentional & 2.73 & 1.92 & 3.54 & 2.51 & 3.29 \\
\hline Intentional assault & 1.56 & 1.42 & 1.71 & 1.64 & 1.60 \\
\hline Intentional self-harm & 1.09 & 1.03 & 1.14 & 1.02 & 1.03 \\
\hline Machinery* & 0.93 & 0.67 & 1.20 & 0.87 & 0.87 \\
\hline Motor vehicle Traffic* & 1.44 & 1.38 & 1.51 & 1.40 & 1.46 \\
\hline Motorcyclist & 1.31 & 1.06 & 1.57 & 1.70 & 0.84 \\
\hline Occupant & 1.50 & 1.42 & 1.58 & 1.47 & 1.69 \\
\hline Pedalcyclist & 1.42 & 0.95 & 1.89 & 1.46 & 1.53 \\
\hline Pedestrian & 1.34 & 1.16 & 1.52 & 1.19 & 1.26 \\
\hline Natural/environmental ${ }^{*}$ & 0.57 & 0.41 & 0.74 & 0.61 & 0.48 \\
\hline Pedal cyclist, non-MV* & 2.07 & 1.55 & 2.60 & 1.93 & 1.20 \\
\hline Pedestrian, non- $\mathrm{MV}^{*}$ & 1.23 & 0.82 & 1.65 & 0.99 & 1.00 \\
\hline Struck by/against* & 2.79 & 2.43 & 3.16 & 2.28 & 2.24 \\
\hline Unintentional & 1.97 & 1.63 & 2.31 & 1.55 & 1.47 \\
\hline Intentional assault & 5.21 & 4.19 & 6.24 & 4.41 & 4.23 \\
\hline Transport, other* & 1.65 & 1.40 & 1.90 & 1.79 & 1.26 \\
\hline Drowning/submersion $†$ & 0.95 & 0.80 & 1.10 & 0.89 & 0.88 \\
\hline Unintentional & 0.95 & 0.79 & 1.12 & 0.87 & 0.89 \\
\hline Poisoningt & 0.97 & 0.93 & 1.01 & 1.04 & 0.73 \\
\hline Unintentional & 0.26 & 0.25 & 0.28 & 0.20 & 0.15 \\
\hline Intentional self-harm & 1.89 & 1.77 & 2.01 & 2.50 & 2.16 \\
\hline Undetermined & 0.73 & 0.62 & 0.84 & 1.15 & 0.44 \\
\hline Suffocationt & 1.22 & 1.09 & 1.34 & 1.23 & 1.17 \\
\hline Unintentional & 0.67 & 0.57 & 0.77 & 0.69 & 0.74 \\
\hline Intentional self-harm & 1.11 & 0.98 & 1.24 & 1.07 & 1.10 \\
\hline \multicolumn{6}{|c|}{$\begin{array}{l}\text { *Fatal and non-fatal hospitalized injuries with maximum Abbreviated Injury Scale score } \geqslant 3 . \\
\text { FFatal and non-fatal hospitalized injuries, regardless of maximum AIS. } \\
\text { †US hospitalized injury data from 1996-98 National Hospital Discharge Survey. } \\
\text { §US hospitalized injury data based on cause and intent distribution in } 2000 \text { US Health Cost and Utilization Project } \\
\text { (HCUP) Nationwide Inpatient Sample database. } \\
\text { TUS hospitalized injury data based on } 1997 \text { hospital discharge data (HDD) from } 20 \text { states. } \\
\text { RCFR }(\text { NZ:US) = ratio of case fatality rates in NZ v the US. }\end{array}$} \\
\hline
\end{tabular}

country of 5.7 million square kilometers with $81 \%$ of the land making up the continental US whereas NZ is about the size (and population density) of the US state of Colorado-a small, 265000 square kilometer country made up of two main islands (where nearly all of the population lives) and several small outlying islands. About two thirds of the NZ population lives in metropolitan areas and the remainder are spread over rural and sometimes difficult to access land. In the US, about $80 \%$ of the population lives in metropolitan areas.

Trauma surgeons who have practiced in both countries told us they doubted the differences we observed are due to trauma system differences. Nevertheless, organization and coordination of trauma care centers and hospital density differ somewhat. NZ coordinates emergency healthcare at a national level while the US coordinates it at the state and local levels. ${ }^{9}{ }^{10}$ Except in major cities, a NZ trauma patient has only one hospital he or she might logically be taken to; in the US, helicopter transport broadens the choices. Many, but not all, US states triage the most seriously injured to a trauma center that is prepared to deal with severe injuries or a particular injury type (for example, burns). Truly coordinated trauma care in NZ is limited by the availability of only one hospital per location.

Assault injury CFRs are significantly higher in the USpossibly because firearms, a particularly lethal mechanism, are more frequently used in US assaults. Among US assault injuries, $50 \%$ were caused by firearms compared with $8 \%$ in NZ. Among self-inflicted injuries, however, even though a greater proportion of US cases involved firearms, CFRs were not significantly different.

CFRs among motor vehicle injuries may reflect differences in road design and vehicle safety standards. NZ has more rural roads and fewer motorways than the US $(3.9 \% v 6.8 \%$ of road miles). ${ }^{11}$ The lower CFRs in the US may also reflect the regular use of helicopter transport for the seriously injured. It is unclear to what extent elevated CFRs in NZ reflect differences in behaviors that influence the severity of the injury-for example, seat belt and helmet wearing. In 1998, $88 \%$ of NZ front seat drivers and passengers were observed wearing seat belts ${ }^{12}$ and $76 \%$ of children under 5 years of age were observed in approved restraints. ${ }^{13}$ A 1998 US survey observed $70 \%$ of front seat drivers wearing seat belts ${ }^{14}$ and $75 \%$ of parents reported that their child under 6 years rode in a car seat all or most of the time. ${ }^{15}$ Greater restraint use should have reduced the overall crash mortality rate in NZ versus the US, but in reality, worse survival and other factors (for example, more impaired driving ${ }^{16}$ ) resulted in a mortality rate of 12.4 per million kilometers driven in NZ versus 9.4 per million kilometers in the US and a mortality rate of 4.0 per 100 crashes in NZ versus 2.2 per 100 crashes in the US. ${ }^{11}$ 
The lower US firearm injury CFRs may reflect the greater experience in treating these injuries in the US, where the proportion of households owning firearms is twice that of $\mathrm{NZ}^{17}$ and where the firearm injury rate is one of the highest in the world. ${ }^{18}{ }^{19}$ Gun type also seems likely to be influential. In the US, one in six adults owns a handgun and handguns make up about one third of all firearms. ${ }^{20}$ In NZ, where gun laws are more stringent, handguns are effectively prohibited and long guns are found primarily among the farming community. Thus, handguns are an uncommon cause of death in NZ. ${ }^{21}$ The increased CFR in NZ among unintentional injuries may arise because long guns typically propel larger bullets with higher velocities than handguns. Although hospital discharge data rarely coded gun type, mortality data underline the difference in gun types involved. Among the $72 \%$ of $\mathrm{NZ}$ firearm related deaths where gun type was recorded, no handguns were used..$^{22}$ In contrast, handguns accounted for $70-90 \%$ of all fatal firearm injuries in the US. $^{23-25}$

Differences in CFRs for natural/environmental injuries merit exploration. NZ and US geographies are very different and a greater proportion of the NZ population lives rurally. The two countries have different flora and fauna and NZ's climate ranges from tropical to Antarctic; the US is less extreme. The CFR differences could simply be due to differences in exposure to the various risks.

Examining cutting/piercing and struck by/against injury CFRs by intent also revealed marked differences. More detail on the circumstances in the event (for example, cutting instrument type and perpetrator) are needed to understand the observed differences.

The analysis of poisonings and suffocations found significant differences depending on the intent of the injury event. Because all cases regardless of AIS were included, we cannot easily discount the possibility that the observed differences are due to differing admission procedures. Among suicide attempts, which tend to be more lethal, differences may reflect different ways of protecting patients who are a danger to themselves. In the uncoordinated US system patients with minor self-inflicted injuries (most frequently poisonings) are often admitted for a day or two for observation. We see strong indications that the observed poisoning CFR differences by intent reflect coding practices, because the CFRs for poisonings overall are virtually identical in the US and NZ. In the US, suicides are sometimes coded as "unintentional" or "undetermined intent" to assuage survivors or avoid controversy. ${ }^{26}{ }^{27} \mathrm{NZ}$ poisoning deaths miscoded as unintentional rather than self-inflicted could explain the large CFR differences.

Several limitations of our study restrict interpretation of the results. In particular, because $36 \%$ of E codes in the NHDS were modeled probabilistically, some misclassification of cause of injury exists. Extensive sensitivity analysis using two additional US data sets, however, suggested that the differences observed were not artifacts of the cause modeling.

The confidence intervals do not account for the random variation inherent in the counts based on census data (NZ hospitalizations and fatalities, and US fatalities). Causes with small case counts are particularly vulnerable and include natural/environmental, pedestrian non-MV, bicycle non-MV, scald, and self-inflicted injuries.

The data sets were comparable. Because hospital admission procedures vary, particularly for minor injuries, only survivors with the most severe injuries (AIS $\geqslant 3$ ) were included. Nevertheless, it is unknown to what extent remaining unidentified differences in data collection and recording procedures affected the results. Although coding of falls among the elderly is better in NZ than the US ${ }^{28}$ and an examination of US mortality data for the elderly revealed that

\section{Key points}

- Unintentional injuries were more likely to be fatal in New Zealand.

- Intentional assault injuries were more likely to be fatal in the United States.

- Cutting/piercing, firearm, fall, bicycle non-motor vehicle, struck by/against, and motor vehicle injuries were more likely to be fatal in New Zealand than in the United States.

- Natural/environmental injuries and unintentional poisonings and suffocations were more likely to be fatal in the United States.

- The ratio of case fatality rates varied slightly by age group.

- Possible reasons for the differences include coding practices, policies, trauma services, population demographics, and environmental factors.

coding choices seem to affect fall death rates, ${ }^{29}{ }^{30}$ our study found little age related difference between fall CFRs.

The observed differences in this analysis are provocative and merit investigation. They suggest hypotheses to test in future research probing the reasons for the differences and guiding priority setting and intervention. Some issues raised by this study might be clarified by using additional years of data, comparing trends and policies over time, and comparing these findings with comparable data sets from other countries.

\section{ACKNOWLEDGEMENTS}

Partial funding for this project came from grant 1 R01 MH60622 from the National Institute of Mental Health. The Injury Prevention Research Unit is jointly funded by the Health Research Council of New Zealand and the Accident Compensation Corporation. The New Zealand data were supplied by the New Zealand Health Information Service. The authors acknowledge the International Collaborative Effort (ICE) on Injury Statistics for contributions to this research. The ICE is sponsored by the National Center for Health Statistics, US Centers for Disease Control and Prevention with funding from the National Institute of Child Health and Development, National Institutes of Health. The views expressed in this paper are those of the authors and do not necessarily reflect those of the above organizations.

\section{Authors' affiliations}

R Spicer, T Miller, Pacific Institute for Research and Evaluation, Calverton, MD, USA

J Langley, S Stephenson, Injury Prevention Research Unit, Dunedin, New Zealand

\section{REFERENCES}

1 Centers for Disease Control and Prevention. Web-based Injury Statistics Query and Reporting System (WISQARS), Available at www.cdc.gov/ncipc/ wisqars (accessed 17 September 2004).

2 National Center for Health Statistics (NCHS). International Classification of Diseases, 9th revision: Clinical Modification. Hyattsville, MD: Department of Health and Human Services; 1980, PHS 80-, 1260.

3 Miller TR, Romano ED, Spicer RS. The cost of childhood unintentional injuries and the value of prevention. Future Child 2000;10:137-63.

4 Association for the Advancement of Automotive Medicine. The abbreviated injury scale. Des Plaines, IL: Association for the Advancement of Automotive Medicine, 1990.

5 Johns Hopkins University, Tri-Analytics Inc. ICDMAP-90 Software user's guide 1997.

6 Centers for Disease Control, Prevention (CDC). Recommended framework for presenting injury mortality data. Morb Mortal Wkly Rep 1997;46(RR-14).

7 Centers for Disease Control and Prevention. National Hospital Discharge Survey 1996 Public Use Data Tape Documentation. Hyattsville, MD: National Center for Health Statistics, 1996. 
8 Central Intelligence Agency (CIA). The World Fact Book, 2004. Available at http://www.studentsoftheworld.info/infopays/wfb/def/2066rank.php (accessed 16 September 2004).

9 Civil I, Twaddle B. Trauma care systems in New Zealand. Injury 2003;34:740-4.

10 Blackwell T, Kellam JF, Thomason M. Trauma care systems in the United States. Injury 2003;34:735-9.

11 Organization for Economic Cooperation, Development/European Conference of Ministers (OECD/ECM). International Road Traffic and Accident Database, Available at: www.bast.de/htdocs/fachthemen/irtad/ englisch/english.html (accessed 14 September 2004).

12 New Zealand Land Transport Safety Authority. Child restraint survey: Results of national survey, December 2003, Available at: www.ltsa.govt.nz; research/belts2.html (accessed 26 September 2004).

13 New Zealand Land Transport Safety Authority. Seat belt wearing by adult front seat occupants: results of a national survey, 2004. New Zealand Land Transport Safety Authority. Available at www.ltsa.govt.nz/research/ belts3.html (accessed 26 September 2004).

14 National Highway Traffic Safety Administration (NHTSA). Observed safety belt use in 1998. National Highway Traffic Safety Administration (NHTSA), September 1999. Available at http://www.nhtsa.dot.gov/people/injury/ airbags/buckleplan/BUA_WEBSITE/Archive-04/buckleup/ RNMT98.WP8.html (accessed 26 September 2004).

15 Block A. Motor vehicle occupant safety survey: Volume 3, Child safety seat report. Office Of Research and Traffic Records, National Highway Traffic Safety Administration, July, 2000. Available at http://www.nhtsa.dot.gov/ people/injury/research/safetysurvey/1998_vol3/cssr_index.htm /accessed 26 September 2004).

16 Miller TR, Blewden M. Costs of alcohol-related crashes: New Zealand estimates and suggested measures for use internationally. Accid Analy Prev 2001;33:783-91.

17 Killias M. International correlations between gun ownership and rates of homicide and suicide. Can Med Assoc J 1993;148:1721-5.
18 Fingerhut LA, Cox CS, Warner M. International comparative analysis of injury mortality. Findings from the ICE on injury statistics. International Collaborative Effort on Injury Statistics. Advance data from vital and health statistics; no. 303. Hyattsville, MD: National Center for Health Statistics, 7 October 1998.

19 Krug EG, Dahlberg LL, Powell KE. Childhood homicide, suicide, and firearm deaths: An international comparison. World Health Stat $Q$ 1996;49:230-5.

20 Cook PJ, Ludwig J. Guns in America: National survey on private ownership and use of firearms, Washington D.C. : National Institute of Justice, 1997.

21 Norton R, Langley J. Firearm related deaths in New Zealand 1978-87. N Z Med J 1993; 106:463-5.

22 Injury Prevention Research Center. Guns in New Zealand. Injury Prevention Research Center: Auckland, New Zealand, 1996.

23 Hargarten SW, Karlson TA, O'Brien $M$, et al. Characteristics of firearms involved in fatalities. JAMA 1996;275:42-5.

24 Kellerman AL, Rea DT. Protection or peril? An analysis of firearm-related deaths in the home. N Eng J Med 1986;314:1557-60.

25 Le RK, Waxweiler RJ, Dobbins JG, et al. Incidence rates of firearm injuries in Galveston, Texas, 1979-1981. Am J Epidemiol 1991;134:511-21.

26 Hlady WG, Middaugh JP. The underrecording of suicides in state and national records, Alaska 1983-1984. Suicide Life Threat Behav 1988;18:237-44.

27 Mohler B, Earls F. Trends in adolescent suicide: misclassification bias? Am J Public Health 2001;91:150-3.

28 Langlois JA, Smith GS, Baker SP, et al. International comparisons of injury mortality in the elderly: Issues and differences between New Zealand and the United States. Int J Epidemiol 1995;24:136-43.

29 Lawrence BA, Miller TR, Weiss HB. Does underlying cause of death count injury deaths accurately? Paper presented at: American Public Health Association Conference; May, 2002; Philadelphia, PA.

30 Fingerhut LA, Weiss HB, Koehler S, et al. Are we undercounting fall-related deaths in the United States? Safe USA Conference, December 2001, Atlanta: GA, 2001.

\section{LACUNAE}

\section{Fine for phone chat on bike}

$\mathrm{P}$ olice on Queensland's Gold Coast weren't taking Michael Dailey for a ride in May when they slapped him with a \$225 fine for talking on his mobile phone while cycling. The 44 year old cleaner said he was "shocked" when he was booked by police from the State Traffic Taskforce. The case provoked sympathy yesterday, criminal lawyer Bill Potts said "It's completely over the top. One would have thought that a sensible police officer if he felt there was any danger, would have simply, in his best Mr Plod voice, said, 'be careful in future"'. But the Queensland Police Service defended its officers yesterday, saying uniform national laws prohibited people from talking on a mobile phone while driving any vehicle, including a bicycle.

The Australian, May 2004. Contributed by Ian Scott. 